\title{
Равновесная сорбция метиленового голубого на клиноптилолите
}

\author{
Котова Д.Л., Сокрюкина А.И., Крысанова Т.А. \\ ФГБОУ ВО «Воронежский государственный университет», Воронеж
}

Поступила в редакцию 1.03.2019 г.

DOI: https://doi.org/10.17308/sorpchrom.2019.19/735

Изучена равновесная сорбция метиленового голубого на нативном и кислотноактивированном клиноптилолите. Выявлен характер сорбции красителя на алюмосиликате, проявляющийся в образовании монослоя и формировании ассоциатов метиленового голубого. Сорбция из разбавленных растворов красителя описывается уравнением Лэнгмюра. Установлено увеличение удельной поверхности сорбента и его сорбционной способности с ростом концентрации активатора.

Ключевые слова: сорбция, метиленовый голубой, клиноптилолит.

\section{Equilibrium sorptionof methylene blue on clinoptilolite}

\author{
Kotova D.L., Sokryukina A.I., Krysanova T.A. \\ Voronezh State University, Voronezh
}

To expand the scope of aluminosilicates, in particular, clinoptilolite, as carriers and sorbents, various ways of their modification are used. The effect of acid activation on the structural characteristics of aluminosilicate can be determined by experimental data of the study of the equilibrium of sorption of methylene blue (MG). Sorption fixation of MG allows to get an idea about the surface of clinoptilolite formed by pores more than $1.5 \mathrm{~nm}$. The object of the analysis was selected organic dye - methylene blue, sorbent - clinoptilolite frame aluminosilicate (deposits of the Subpolar Ural of Ugra) in the native and activated with hydrochloric acid state. The equilibrium of MG sorption on acid-activated clinoptilolite was studied at a temperature of $295 \pm 2 \mathrm{~K}$ under static conditions by the method of variable concentrations. The interval of used MG concentrations was $0.150-4.0 \mathrm{mmol} / \mathrm{dm}^{3}$.

An S-shaped type of isotherms was revealed, which suggests a change in the mechanism of sorption fixation of MG with an increase in its concentration in the external solution. In the region of low concentrations of the dye solution, the formation of a monolayer of sorbate is observed. For a quantitative description of the sorption equilibrium in the concentration range corresponding to the formation of a monolayer, the Langmuir equation was used. The presentation of the experimental data of the equation in a linear form made it possible to determine the limiting capacity of the monolayer, the specific surface area and the coefficient of sorption equilibrium. Monolayer fixation of MG in the form of cation on the native sample of clinoptilolite is possible as a result of an equivalent exchange with non-carcass cations due to electrostatic interaction with available negatively charged centers of the sorbent matrix. After completion of the formation of the monolayer, sorption acquires a polymolecular character, which is manifested on the isotherm in a sharp increase in the sorption capacity due to the presence in the solution of dye associates formed as a result of Van der Waals interactions and hydrogen bonds.

Keywords: sorption, methyleneblue, clinoptilolite.

\section{Введение}

Проблема получения алюмосиликатов с заданной функциональностью и гидрофильно-гидрофобным балансом успешно решается различными способами их мо- 
дификации, что значительно расширяет применение их как наноразмерных матриц, носителей и сорбентов [1-5]. Одним из представителей каркасных алюмосиликатов является клиноптилолит, обладающий целым набором свойств, обуславливающих его практическое применение. Химический состав и структура поверхностного слоя оказывают непосредственное влияние на сорбционные свойства клиноптилолита. Кислотная модификация алюмосиликата обеспечивает изменение его текстурных и гидрофильно-гидрофобных свойств. Влияние кислотной активации на структурные характеристики алюмосиликата можно определить по экспериментальным данным исследования равновесия сорбции метиленового голубого [6, 7]. Сорбционное закрепление МГ позволяет получить представление о поверхности клиноптилолита, образованной порами более 1.5 нм.

Целью данной работы явилось исследование равновесия сорбции метиленового голубого на нативном и кислотно-активированном клиноптилолите.

\section{Эксперимент}

Метиленовый голубой (МГ, N,N,N',N' - тетраметилтионина хлорид тригидрат) - органический основный краситель, относящийся к группе тиазиновых красителей. В области значений $\mathrm{pH}$ от 2 до 10 метиленовый голубой присутствует в водном растворе преимущественно в виде однозарядного катиона [8]. Брутто - формула МГ$\mathrm{C}_{16} \mathrm{H}_{18} \mathrm{~N}_{3} \mathrm{SCl}$, структурная формула [9]:<smiles></smiles>

В качестве сорбента выбран каркасный алюмосиликат клиноптилолит (месторождение Приполярного Урала Югры), рекомендованный в качестве энтеросорбента Климонт.

Сорбцию метиленового голубого проводили на нативном и активированном соляной кислотой сорбенте. Кислотное активирование клиноптилолита осуществляли обработкой раствором 1.0; 3.0; 4.0 и 5.0 М соляной кислоты. Предварительно определив влажность, 1.0 г клиноптилолита приводили в контакт с $100.0 \mathrm{~cm}^{3}$ раствора кислоты заданной концентрации и выдерживали при температуре $295 \pm 2 \mathrm{~K}$ при перемешивании в течение времени, необходимого для установления равновесия. Сорбент отделяли от раствора фильтрованием и отмывали дистиллированной водой до отсутствия в растворе хлорид-ионов.

Равновесие сорбции метиленового голубого на активированном кислотой клиноптилолите исследовали при температуре $295 \pm 2$ К в статических условиях методом переменных концентраций. Интервал используемых концентраций МГ соста-

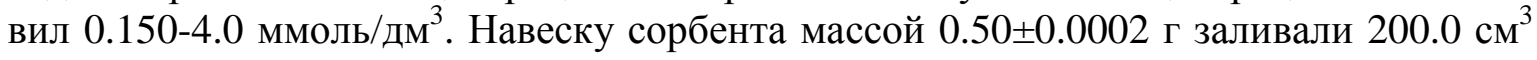
раствором МГ заданной концентрации и выдерживали при постоянном перемешивании в течение 4 часов. Время установления равновесия в системе предварительно определено из кинетического эксперимента. Равновесные фазы разделяли, и раствор анализировали на содержание красителя методом спектрофотометрии при $\lambda=660 \mathrm{Hм}$ $\left(\mathrm{S}_{\mathrm{r}}=0.03\right)$. Количество сорбированного МГ определяли по разности концентраций до и после контакта с раствором сорбата.

Установлено [10], что при обработке клиноптилолита кислотой происходит обмен внекаркасных катионов на ион водорода и деалюминирование. С ростом концентрации кислоты степень деалюминирования увеличивается, что проявляется в

Котова и др. / Сорбционные и хроматографические процессы. 2019. Т. 19. № 2 
изменении параметра Si/Al. В процессе удаления алюминия из каркаса уменьшается электроотрицательность матрицы сорбента, и образуются как изолированные, так и связанные между собой водородными связями силанольные группы. Следует отметить, что активирование клиноптилолита $5.0 \mathrm{M}$ кислотой приводит к его частичной аморфизации.

\section{Обсуждение результатов}

Изотермы сорбции метиленового голубого на нативном и активированном соляной кислотой клиноптилолите приведены на рис.1. S-образный вид изотерм предполагает изменение механизма сорбционного закрепления МГ с ростом его концентрации во внешнем растворе. Линейная зависимость и образование плато на изотерме в области малых концентраций раствора красителя отвечают образованию монослоя. МГ сорбируется в мономерной форме.

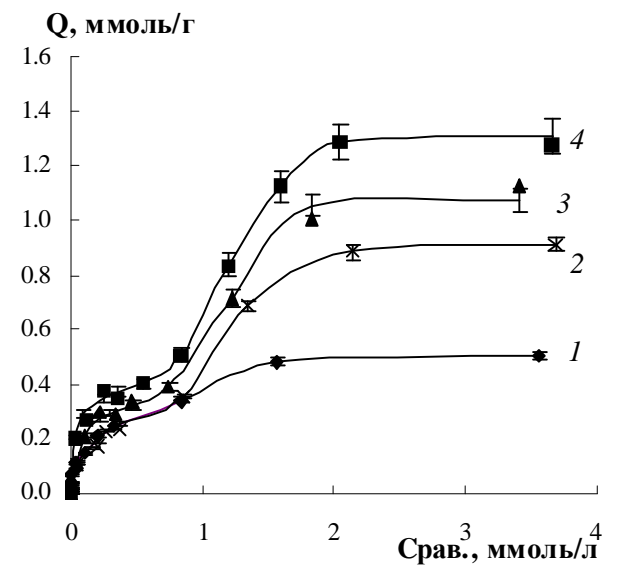

Рис.1 Изотермы сорбции метиленового голубого на нативном (1) и активированном $2.0 \mathrm{M} \mathrm{(2);} 4.0 \mathrm{M} \mathrm{(3);} 5.0 \mathrm{M} \mathrm{HCl}$ (4) клиноптилолите

Для количественного описания равновесия сорбции в интервале концентраций, соответствующих образованию монослоя, применяли уравнение Лэнгмюра [11]:

$$
Q=\frac{Q_{\infty K C_{\mathrm{paB}}}}{1+K C_{\mathrm{pas}}}
$$

где К- коэффициент сорбционного равновесия, характеризующий интенсивность процесса сорбции, дм ${ }^{3} /$ моль; Q - количество сорбированного красителя, ммоль/г; $\mathrm{C}_{\text {рав. }}-$ равновесная концентрация МГ в растворе, ммоль/дм ${ }^{3} ; \mathrm{Q}_{\infty}-$ предельная емкость монослоя, ммоль/г. Модель Лэнгмюра предполагает наличие определенного числа активных центров с одним и тем же сорбционным потенциалом. Представление экспериментальных данных в линейной форме позволило определить предельную емкость монослоя, удельную поверхность и коэффициент сорбционного равновесия (таблица).

Полученные значения коэффициентов корреляции при линеаризации изотерм указывают на удовлетворительное соответствие изотермы уравнению Лэнгмюра в данном диапазоне концентраций. Удельную поверхность $\left(S_{\text {уд }}\right)$ рассчитывали, используя выражение [12]:

$$
\mathrm{S}_{\mathrm{yd}}=\mathrm{Q}_{\infty} \cdot \mathrm{N}_{\mathrm{a}} \cdot \omega_{\mathrm{m}},
$$

где $\mathrm{Q}_{\infty}$ - емкость монослоя, ммоль/г; $\mathrm{N}_{\mathrm{a}}$ - число Авогадро, равное $6.02 \cdot 10^{23}$ моль $^{-1}$; $\omega_{\mathrm{m}}$ - площадь, занимаемая молекулой сорбата (элементарная площадка для $\mathrm{M \Gamma} \approx 0.57 \cdot 10^{-18} \mathrm{M}^{2}$ ). С ростом концентрации активатора отмечается возрастание удельной поверхности алюмосиликата. 
Таблица. Сорбционные характеристики нативного и активированного соляной кислотой клиноптилолита

\begin{tabular}{|c|c|c|c|c|}
\hline Сорбент & $\mathrm{Q}_{\infty .}$, ммоль/Г (мг/г) & $\mathrm{K}$, дм $^{3} /$ моль & $\mathrm{S}_{\text {уд }} \mathrm{m}^{2} / \Gamma$ & $\mathrm{R}^{2}$ \\
\hline Нативный & $0.37(118.4)$ & 5.75 & 127 & 0.97 \\
\hline обработанный $1.0 \mathrm{M} \mathrm{HCl}$ & $0.40(120.0)$ & 6.02 & 137 & 0.98 \\
\hline обработанный $3.0 \mathrm{M} \mathrm{HCl}$ & $0.42(134.4)$ & 6.52 & 144 & 0.97 \\
\hline обработанный $4.0 \mathrm{M} \mathrm{HCl}$ & $0.44(140.8)$ & 9.16 & 151 & 0.98 \\
\hline обработанный $5.0 \mathrm{M} \mathrm{HCl}$ & $0.46(147.2)$ & 10.50 & 158 & 0.98 \\
\hline
\end{tabular}

Монослойное закрепление МГ в виде катиона на нативном образце клиноптилолита возможно в результате эквивалентного обмена с внекаркасными катионами за счет электростатического взаимодействия с доступными отрицательно заряженными центрами матрицы сорбента. Изменение химической природы активных центров, увеличение пористости с ростом концентрации активатора проявляются в более выраженном на изотерме плато и увеличении количества МГ, участвующего в образовании монослоя. Для клиноптилолита, обработанного $4.0 \mathrm{M}$ соляной кислотой, отмечается рост монослойной емкости по сравнению с нативным в 1.2 раза.

После завершения формирования монослоя сорбция приобретает полимолекулярный характер, что проявляется на изотерме в резком увеличении сорбционной емкости. Авторами работы [13] отмечается способность МГ к образованию димеров при концентрации раствора красителя более $1 \cdot 10^{-3} \mathrm{M}$. С ростом концентрации в растворе могут присутствовать ионы красителя и его ассоциаты, образованные в результате Ван-дер-Ваальсовых взаимодействий и водородных связей [14].

Сорбционная активность алюмосиликата к соединениям, способным образовывать ассоциаты, определяется размерами пор и удельной поверхности. Следует отметить, что в процессе обработки клиноптилолита соляной кислотой наблюдается увеличение первичной и вторичной пористости [15]. Активация сорбента $4.0 \mathrm{M}$ кислотой приводит к росту объема мезопор в 2 раза. Для сорбента, активированного 4.0 M HCl, значение максимального сорбционного параметра составляет 1.15 ммоль/г, что в 2.3 раза превышает его величину для нативного.

\section{Заключение}

Равновесная сорбция метиленового голубого на нативном и кислотно- активированном клиноптилолите характеризуется образованием монослоя и формированием ассоциатов. Сорбция из разбавленных растворов красителя описывается уравнением Лэнгмюра. Установлено увеличение удельной поверхности сорбента и его сорбционной способности с ростом концентрации активатора.

\section{Список литературы}

1. Garcia Basabe Y., Rodriguez Iznaga I., de Menorval L.C. et al. // Micropor. Mesopor. Mater. 2010. Vol. 135. pp. 187.

2. Çakicioglu-Ozkan F., Ülkü S. // Microporous and Mesoporous Materials. 2005. Vol. 77. pp. 47-53.

3. Beyer H.K. // Molecular Sieves - Science and Technology. Vol. 3. Ed. By Karge G.H. and Weitkamp J. Berlin. Springer. 2002. P. 203.
4. Sprynskyy M., Golembiewski R., Trykowski G. // J. of Physics and chemistry of solids. 2010. Vol. 71. pp. 1269-1277.

5. Ciahotny K., Melenova L., Jirglova H. et al. // Adsorption. 2006. Vol. 12. pp. 219-226.

6. Графит. Методы определения удельной поверхности (с изменением N1). ГОСТ 13144-79- Введ. 1981-01-01. М. Изд-во стандартов. 1999.

7. Глина бентонитовая для тонкой и строительной керамики. Методы определе- 
ния показателя адсорбции и емкости катионного обмена: ГОСТ 21283 -93- Введ. 199501-01. М. Изд-во стандартов. 1995.

8. Simitzis J., Sfyrakis G. // Journal Applied Polymer Seince. 1994. Vol. 54. No 13. pp. 2091-2099.

9. Наянова Е.В., Елипашева Е.В., Сергеев Г.М. и др. // Аналитика и контроль. 2015. № 2. C. $154-160$.

10. Котова Д.Л., До Тхи Лонг, Крысанова Т.А. и др. // Изв. вузов. Химия и химическая технология. 2012. Т. 55. № 4. С. 100-104.

11. Фролов Ю.Г. Курс коллоидной химии. Поверхностные явления и дисперсные системы. М. Химия. 1989. 464 с.

\section{References}

1. Garcia Basabe Y., Rodriguez Iznaga I., de Menorval L.C. et al., Microporous and Mesoporous Materials, 2010, Vol. 135, P. 187.

2. Çakicioglu-Ozkan F., Ülkü S., Microporous and Mesoporous Materials, 2005, Vol. 77, pp. 47-53.

3. Beyer H.K., Molecular Sieves - Science and Technology, Vol. 3. Ed. By Karge G.H. and Weitkamp J. Berlin: Springer, 2002, P. 203.

4. Sprynskyy M., Golembiewski R., Trykowski G., J. of Physics and chemistry of solids, 2010, No 71, pp. 1269-1277.

5. Ciahotny K., Melenova L., Jirglova H. et al., Adsorption, 2006, Vol. 12, pp. 219-226.

6. Grafit. Metody opredeleniya udelnoy poverhnosty (s Izmeneniem N 1),: GOST 1314479-Rec, 1981-01-01, M., Standards Publishing House, 1999.

7. Glina bentonitovaya dlya tonkoy i stroitel'noy keramiki. Metody opredeleniya pokazatelya adsorbtsii i yomkosti kationnogo obmena. GOST 21283-93- Rec, 1995-01-01. - M. Standards Publishing House, 1995.

Котова Диана Липатьевна - профессор кафедры аналитической химии, д.Х.н., Воронежский государственный университет, Воронеж

Сокрюкина Анна Ивановна - студент кафедры аналитической химии, Воронежский государственный университет, Воронеж.

Крысанова Татьяна Анатольевна - доцент кафедры аналитической химии, к.х.н., Воронежский государственный университет, Воронеж
12. Джайлс Ч., Ингрем Б, Клюни Дж. и др. Адсорбция из растворов на поверхности твердых тел. М. Мир. 1986. 488 с.

13. Tafulo R.A.R., Queiros R.B., Conzaler G.A. // Spectrochem. Acte. 2009. Vol. 76. pp. 295-300.

14. Мельников Б.Н., Виноградова Г.И. Применение красителей. М. Химия. 1986. $240 \mathrm{c}$.

15. Котова Д. Л., Васильева С. Ю., Крысанова Т. А. и др. // Российские нанотехнологии. 2014. Т. 9. № 9-10. С. 474-479.

8. Simitzis J., Sfyrakis G., Journal Applied Polymer Science, 1994, Vol. 54, No 13, pp. 2091-2099.

9. Nayanova E.V., Elipasheva E.V., Sergeev G.M. et al., Analitics and control, 2015, No 2, pp. 154-160.

10.Kotova D.L., Do Thi Long, Krysanova T.A. et al., News of universities. Chemistry and chemical technology, 2012, Vol. 55, No 4, pp. 100-104.

11.Frolov Yu.G., Kurs kolloidnoy himii. Poverhnostnye yavleniya i dispersnye sistemy, M., Chemistry Publ., 1989, 464 p.

12.Dzhails Ch., Ingrem B., Klyni J. et al., Adsorbtsiya iz rastvorov na poverhnosti tvyordyh tel. M., Mir, 1986, 488 p.

13.Tafulo R.A.R., Queiros R.B., Conzaler G.A., Spectrochem. Acte, 2009, Vol. 76, pp. 295-300.

14.Mel'nikov B.N., Vinogradova G.I., Primenenie krasiteley, M., Himiya Publ., 1986, $240 \mathrm{p}$.

15.Kotova D.L., Vasil'eva S.Yu., Krysanova T.A. et al., Russian nanotechnology, 2014, Vol. 9, No 9-10, pp. 474-479.

Kotova Diana L. - prof., grand Ph.D (chemistry), department of analytical chemistry, Voronezh State University, Voronezh

Sokrukina Anna I. - the student, department of analytical chemistry, Voronezh State University, Voronezh

Krysanova Tatiana A. - Ph.D. (chemistry), associate prof., department of analytical chemistry, Voronezh State University, Voronezh, E-mail: takrys@yandex.ru 